\title{
Tobacco commerce on the internet: a threat to comprehensive tobacco control
}

\begin{abstract}
Although internet use continues to increase and e-commerce sales are expected to exceed US\$1 trillion by the end of 2001, there have been few assessments in the literature regarding the implications of this medium for tobacco control efforts. This commentary explores the challenges that the internet may pose to the key components of a comprehensive tobacco control strategy, and pinpoints potential approaches for addressing these challenges. Four key challenges that the internet presents for tobacco control are identified: unrestricted sales to minors; cheaper cigarettes through tax avoidance and smuggling; unfettered advertising, marketing and promotion; and continued normalisation of the tobacco industry and its products. Potential strategies for addressing these challenges include international tobacco control agreements, national and state regulation, and legal remedies.
\end{abstract}

Globalisation of commerce, investments, and finance is the dominant paradigm among the world's economic and political leaders. ${ }^{12}$ Not only is the internet a major component of globalisation, but it also appears to be a driver of this movement. ${ }^{3}$ This revolutionary force has changed the mass media landscape in ways that would have been difficult to predict a mere decade ago. Much debate has transpired over the content and regulation of this new frontier, and the issues are complex and evolving. A tension has developed between accessibility to information and commerce, on one hand, and policies and laws designed to protect the citizenry and uphold social values, on the other.

By the end of 2000, internet usage had grown to an estimated 374.9 million users in the top 15 user nations, with 490 million users (79.4 per 1000 people) projected by $2002 .{ }^{4}$ Sales by e-commerce reached US $\$ 657$ billion worldwide by the end of 2000, and are projected to reach $\$ 1.2$ trillion worldwide by the end of 2001 and $\$ 6.8$ trillion by end of $2004 .^{5}$ Although some tobacco spokespersons deny plans to market their products on the web, ${ }^{6}$ the tobacco industry is clearly cognizant of the power of the internet and is working to position itself favourably in this new market. ${ }^{7}$ Tobacco industry experts predict that within 10 years, at least one fifth of the $\$ 40$ billion in annual US cigarette sales will occur over the internet. $^{8-10}$

Numerous issues may have to be addressed if tobacco control efforts are to keep pace with commerce on the internet. Of critical importance is whether tobacco e-commence threatens the integrity of comprehensive tobacco control programmes, and if so, how this will materialise. Below we describe the challenges the internet may pose to the key components of a comprehensive strategy, and suggest potential solutions for addressing these challenges drawing on developments already occurring.

\section{Challenges for tobacco control}

UNRESTRICTED SALES TO MINORS

The prevention of sales to minors is a key component of a comprehensive tobacco control strategy, ${ }^{11}$ but it is clear that there are few barriers to youth buying cigarettes online. A state investigation in Utah found that children aged 10-17 were able to obtain cigarettes with ease via the internet. ${ }^{8}$ In an Oregon undercover investigation, four internet based tobacco dealers were found to have sold cigarettes to children as young as 8 years old. ${ }^{12} \mathrm{~A}$ recent study also found that cigar sites on the internet have few barriers to purchases by minors. ${ }^{13}$ Further, filter software fails to protect children adequately from promotional tobacco content. ${ }^{14}$

CHEAPER CIGARETTES THROUGH TAX AVOIDANCE AND SMUGGLING

Price controls are another key element in a comprehensive tobacco control strategy ${ }^{11}$ and young people are particularly price sensitive. ${ }^{15}$ However, internet tobacco sales offer an attractive route for many consumers seeking cheaper cigarettes, through the avoidance of tobacco taxes. Tax based tobacco control initiatives are often undermined and delayed by the argument that such measures will fuel smuggling and other criminal activity. Internet tobacco commerce can also fuel these problems, because it can be a source of legal tax-free cigarettes that are then resold illegally by intermediaries. For example, Seneca Indian reservations in New York State have over three dozen websites selling tax-free cigarettes. ${ }^{16}$ Recently, in Canada, a two year investigation found that $85 \%$ of all cigarettes sold tax-free by the Squamish Nation in British Columbia was diverted to buyers who then resold the product to non-natives for profit. ${ }^{17}$ An investigation is underway in Ireland regarding the importation of duty-free cigarettes using the internet. ${ }^{18}$

One popular internet cigarette site (www.discount-cigarettes.org) requires retailers listed on the site to fully disclose on their home page if they report customer names to state tax agencies. It also lists many sites that specifically indicate that they do not report names to state tax departments. This is despite 
the Jenkins Act, a US federal statute that requires anyone selling cigarettes in interstate commerce to report those sales to the tobacco tax administrator for that state into which the sales are made. ${ }^{19}$

UNFETTERED ADVERTISING, MARKETING, AND PROMOTION

Comprehensive tobacco control programmes employ strategies to counter directly the advertising, marketing, and promotional activities of the tobacco industry. ${ }^{11}$ The internet is a powerful marketing tool for use by an industry with demonstrated prowess in sophisticated market manipulation. ${ }^{20}$ At least one study suggests a relation between online advertising and tobacco consumption. ${ }^{14}$

Smoking sites glamourise tobacco use. ${ }^{21}$ The smoking section site (http:// smokingsection.com) even provides "A smoker's guide to the cool ways to smoke", and other tobacco sites include elements that appeal to youth. ${ }^{13}$ British American Tobacco (BAT) has sponsored a web site, "City Gorilla", that purportedly provides "independent" advice on night life; however, the site features venues that promote and sell BAT cigarettes, and it collects information on smokers that could be used for marketing purposes. $^{22}$

CONTINUED NORMALISATION OF THE TOBACCO INDUSTRY AND ITS PRODUCTS

In Canada and the USA, denormalisation of the tobacco industry and its products is also regarded as a key strategy in a comprehensive approach to tobacco control. ${ }^{23}{ }^{24}$ Tobacco sales on the internet offer a venue for the continued normalisation of these products by casting them as just another consumer item. Unrestricted cigarette sales to minors, cheap cigarettes, and unfettered cigarette advertising, marketing and promotion contribute to the normalisation of these products.

\section{Potential solutions for addressing on-line} challenges to tobacco control

Delay in regulating tobacco e-commerce could be deleterious to the public's health. The market continues to be driven forward by high consumer expectations and demands, and buoyed by technological advances. Relevant public policy and regulatory controls are clearly lagging behind in their development and new issues continue to surface-for example, BAT's City Gorilla site. However, there is no easy "fix" for the challenges posed by tobacco commerce on the internet. Solutions must be implemented on many fronts.

INTERNATIONAL TOBACCO CONTROL

The tobacco industry knows that e-commerce offers the industry "a chance not to be missed" as "it's difficult to imagine individual countries attempting to regulate cyber-space". ${ }^{7}$ The proposed World Health Organization Framework Convention on Tobacco Control (FCTC) is being negotiated by the member states of WHO, with a target date of adoption of $2003 .{ }^{25}{ }^{26}$ The FCTC provides an opportunity to promote international cooperation and coordination of tobacco control efforts, particularly where the challenges are transboundary in nature. Potentially important areas that have been identified for protocol development include: tobacco smuggling; duty-free sales of tobacco; tobacco pricing and taxation; and reporting of production, sales, imports, and exports of tobacco products. Because of the inherently global nature of the world wide web, it has the potential to impact upon and challenge all aspects of international tobacco control. Although recent versions of the FCTC require parties to commit to adopting national measures and cooperating to phase out cross-border advertising, promotion and sponsorship on the internet and through other media, initiatives to address internet tobacco commerce are not yet an explicitly stated priority. ${ }^{27}$ Internet tobacco sales should be included as a key focus of the FCTC and other international agreements.

NATIONAL AND STATE REGULATION

Several bills are pending in the USA at state and national levels that would increase restrictions on the internet sale of tobacco. ${ }^{9}$ Measures include making it easier for states to prosecute out-of-state web sites that sell tobacco to minors, to prohibit on-line sales, and to mandate websites selling tobacco to display the surgeon general's warning. ${ }^{9}$ Following an investigation in Oregon, four internet based tobacco dealers signed an agreement not to sell their products to minors, or potentially face fines up to $\$ 25000$ for each occurrence. ${ }^{12}$

New York State passed a law banning internet, mail, and telephone cigarette orders from being sent directly to consumers, which was scheduled to take effect on 1 January 2001. However, Brown \& Williamson Tobacco challenged the law claiming that "The Constitution prohibits any one state from regulating avenues of national commerce such as the Internet . . .", ${ }^{28}$ and a federal judge ruled that the law did violate the commerce clause of the US Constitution. ${ }^{29}$ In Rhode Island, internet distributors can be fined if they sell cigarettes to a $\operatorname{minor}^{30}$; distributors will have to obtain customer IDs, and an adult will have to sign on delivery. ${ }^{31}$ The attorneys general from 17 US states have joined in an effort to halt online sales of bidis (flavoured, hand rolled cigarettes) to children by sending letters asking the companies to stop selling to minors. ${ }^{32}$

The advertising potential of the internet has not gone unnoticed and the US Department of Justice issued an opinion in 1998 affirming the Food and Drug Administration's authority, in the interest of comprehensive tobacco legislation, to extend prohibitions on tobacco advertising on television and radio to include the internet. ${ }^{33}$ In the UK, the proposed Tobacco Advertising and Promotions Bill would prohibit UK based internet service providers from selling space to cigarette advertisers. ${ }^{34}$ In China, the Law of Network Advertisement bans on-line advertisements for cigarettes and sexual products. ${ }^{35}$ 
There are precedents for regulating the on-line sale of particular goods, in particular, alcohol and prescription drugs. In the USA, widely disparate state laws have created conflicts around the sale of alcohol over the internet. In six states it is a felony to ship alcohol from out of state, and in other states it is a misdemeanour. ${ }^{36}$ Twenty three states ban shipment of alcohol by such carriers as Federal Express or United Parcel Service, ${ }^{37}$ and the states of Oregon and Maryland have bills pending that would make selling alcohol over the internet a felony. ${ }^{38}$ Furthermore, the Food and Drug Administration has submitted legislation to Congress that would require online pharmacies to be licenced in each state in which they operate or deliver prescription drugs and be compliant with state regulations on the practice of medicine and pharmacy. ${ }^{37} \mathrm{By}$ 2000, 28 US states had taken action to regulate internet pharmacies and on-line prescribing by physicians. $^{39}$ Although tobacco is not specifically discussed, the US President's working group on unlawful conduct on the internet recommended that online conduct involving use of the internet should be treated in a manner consistent with the way corresponding offline conduct is treated. ${ }^{40}$

LEGAL REMEDIES

Many jurisdictions across the globe currently prohibit the sale of cigarettes to minors, and these laws could be invoked to press charges against online cigarette retailers. Addressing the illegal sale of tax-free cigarettes could also be an avenue for criminal law remedies.

Governments have begun to address youth's easy access to on-line cigarettes. For example, in December 2000 the Texas attorney general sued E-Commerce Today Ltd, an online tobacco merchant, for failing to take precautions against tobacco sales to minors in that state. ${ }^{41}$ In Michigan, the attorney general recently announced the filing of 20 criminal complaints for selling tobacco and tobacco products to minors via the internet. ${ }^{42}$

California, Washington State, and Alaska have attempted to recover unpaid taxes from sales made by the internet, mail order, and on American Indian reservations, ${ }^{43-45}$ although officials estimate that only $5 \%$ of online or mail order retailers report names and addresses of customers. ${ }^{46}$

\section{Conclusions}

Of course, the internet provides many advantages for tobacco control, in addition to the challenges. For example, the communication and information networks available through the internet are tremendously important for the timely exchange of information between researchers, policymakers, programmers, health professionals, and advocates. ${ }^{47}$ The internet also has the potential of being a key source of information for the lay public regarding the health effects of tobacco use, smoking cessation aids, and the activities of the tobacco industry.

Despite these advantages, we must act to limit the potential disadvantages. Tobacco control is clearly not the only sector grappling with the new challenges being presented by the internet. Regulatory efforts continue to evolve around alcohol and prescription drugs, for example, and legislation in these areas is slowly advancing. The regulation of tobacco related internet commerce and content should, at a minimum, keep up with activity regarding alcohol and prescription drug web sites. Further, the common problems of the vast scope and the dynamic nature of the internet remain issues and suggest the need for proactive rather than reactive solutions.

Although there are regulatory avenues that national and subnational jurisdictions can and should pursue, tobacco e-commerce may be best controlled, in the long run, through international agreements such as the FCTC. Collective action may not only be mutually beneficial, but may be required if our tobacco control strategies are to be effective in this era of globalisation. ${ }^{2}$ If deliberate and concerted action is not taken, tobacco commerce on the internet could prove to be a significant threat to comprehensive tobacco control.

We must also address the dearth of research in the area of internet tobacco sales, marketing, and promotion. We can begin with descriptive data on the epidemiology of on-line tobacco purchasers (for example, age, sex, location of residence, types and amounts of tobacco related on-line purchases, frequency of such purchases, and reasons for purchasing tobacco products on line). Changes in the profiles of these purchasers could be monitored over time. There is also a need for descriptive information on the number of web sites selling tobacco products, promoting tobacco products and their use, and sponsored by the tobacco industry; these sites could be described in terms of various characteristics, including their jurisdiction of origin and their apparent target audience. Analytic studies are required to determine the effects of web based tobacco advertising and promotion on the tobacco related knowledge, attitudes, and behaviours of viewers, and to evaluate the intended and unintended impacts of any internet related interventions.

Policy analysis research is also necessary. Working definitions of on-line tobacco advertising and promotion must be developed. The obstacles to policymaking in this area need to be ascertained, such as impediments related to the inter-jurisdictional reach of the internet and the inter-sectoral interests and responsibilities concerning internet sales, marketing, and promotion of tobacco. Options for addressing these obstacles should be analysed for their feasibility and potential impacts.

\section{JOANNA E COHEN VIVIAN SARABIA* MARY JANE ASHLEY}

Ontario Tobacco Research Unit,

Centre for Health Promotion,

Department of Public Health Sciences,

University of Toronto,

*Community Medicine Residency Program,

University of Toronto, Canada

Toronto, Ontario, Canada 
Correspondence to: Dr Joanna Cohen, Ontario Tobacco Research Unit, University of Toronto, 33 Russell Street,
Toronto, Ontario, Canada M5S 2S1; Joanna_Cohen@camh.net

1 Navarro V. Comment: Whose globalization? Am f Public Health 1998;88:742-3.

2 Yach D, Bettcher D. The globalization of public health, I: threats and opportunities. Am f Public Health 1998;

3 Milio N. The internet, public health, and the globalization of just about everything. I Epidemiol Community Health 2001;55:74-6

4 Internet usage stats. Computer Industry Almanac. April 2001. Accessed at: http://cyberatlas.internet.com

5 Forrester Findings: Internet Commerce. Forrester. April 2001. Accessed at: www.forrester.com/ER.Press/ForrFind/ $0,1768,0,00 . \mathrm{html}$.

6 Allen M. Tobacco proponents and opponents on the Web. New York Times. 18 November 1996.

7 Rethinking the tobacco business. Tobacco fournal International. June 1999 .

8 Noack D. Utah recruits kids to buy smokes online. APBnews.com. February 1, 2000. Accessed at: www.apbnews.com/newcenter/internetcrime/2000/02/01/ www.apbnews.com

9 Said C. Online sale of tobacco drawing a fight. Critics say tax, age laws must apply to Web market. San Francisco tax, age laws must app

10 Online tobacco sale debate intensifies. Foin Together. 31 May 2000. Accessed at: www.jointogether.or

11 United States Department of Health and Human Services. Reducing tobacco use: a report of the Surgeon General. Atlanta, Georgia: US Department of Health and Human Services, Centers for Disease Control and Prevention, National Center for Chronic Disease Prevention and Health Promotion, Office on Smoking and Health, 2000.

12 Beggs CE. Internet tobacco dealers agree not to sell to youths. Associated Press. 8 February 2000. Accessed at: www.canoe.ca/TechNews0002/08_tobacco.html.

13 Malone RE, Bero LA. Cigars, youth, and the Internet link. Am 7 Public Health 2000;90:790-2.

14 Center for Media Education. Youth access to alcohol and tobacco web marketing: the filtering and rating debate. tobacco web marketing: the filtering and rating debate. 1999. Accessed at: www.cme.org/publications/ 1999 . Acces

15 US Department of Health and Human Services. Preventing tobacco use among young people. A report of the Surgeon General, 1994. Atlanta, Georgia: Public Health Service, Centers for Disease Control and Prevention, Office on Smoking and Health, 1994. (US Government Printing Office Publication No S/N 017-001-00491-0.)

16 Beebe M. Tobacco's new road. Taking advantage of technology, the Seneca Indians are making millions tax-free by selling cigarettes on the internet. Buffalo News. 12 December 1999

17 Culbert L. Natives protest cigarette cuts. Vancouver Sun. 20 March 202000.

18 Logue P. Revenue investigating cigarettes for sale on web. The Irish Times/ireland.com, 2001. Accessed at: http:/ scripts.ireland.com/newspaper/breaking/ scripts.ireland.com $/$ news
printable.cfm?id $=21332$

printable.cfm?id=21332
19 Jenkins Act. United States Code; Title 15 (Commerce and Trade); Chapter $10 \mathrm{~A}$ (Collection of State Cigarette Taxes. 23 Trade); Chapter

20 Hanson JD, Kysar DA. Taking behavioralism seriously: some evidence of market manipulation. Harvard Law Review 1999;112:1420-572.

21 Center for Media Education. Tobacco targeted at youth on the internet: an update. Washington DC: Center for Media Education. December, 1998. Accessed at: www.cme.org/ publications/reports.html

22 Rogers D. BAT lures young smokers with 'devious' online scheme. MediaGuardian.co.uk. 24 January 2001. Accessed at: www.mediaguardian.co.uk/marketingandpr/story/ $0,7494,427372,00$. html.
23 Steering Committee of the National Strategy to Reduce Tobacco Use in Canada in Partnership with Advisory Committee on Population Health. New directions for tobacco control in Canada: a national strategy. Her Majesty the Queen in Right of Canada, Represented by the Minister of Public Works and Government Services Canada, 1999.

24 Russell CM. Evaluation: methods and strategy for evaluation - California. Cancer 1998;83(suppl):2755-9.

25 Joosens L. From public health to international law: possible protocols for inclusion in the Framework Convention on Tobacco Control. Bulletin of the World Health Organization 2000;78:930-8.

26 Taylor AL, Bettcher DW. WHO Framework Convention on Tobacco Control: a global "good" for public health. Bulletin of the World Health Organization 2000;78:920-9.

27 World Health Organization. Chair's test of a Framework Convention on Tobacco Control. Geneva: World Health Organization, 9 January 2001.

28 Brown and Williamson News Release. B\&W files suit against New York; says Internet, direct-mail sales ban unconstitutional. Brown and Williamson. 16 October 2000.

29 Interactive Investor International. BAT unit's right to sell cigarettes online, via phone reinstated by U.S. court. $A F X$ Focus. 8 June 2001. Accessed at: www.iii.co.uk/uknews/ articleid=3691889\&action $=$ article

30 Corkery M. Law bans web sale of tobacco to minors. Web Site of the Providence Fournal. 26 October 2000.

31 Internet tobacco law passes. Digital City. 3 July 2000.

32 Rubin R. Kids buying smokes online 13 states warn sites to limit sales of bidis. USA Today. 22 December 1999.

33 United States Department of Justice. Fustice Department statement: Constitutionality of proposed limitations on tobacco industry. Statement before the committee on the judiciary. United States Senate. 13 May 1998.

34 E-Society. Online tobacco ads Bill goes up in smoke. Silicom.com. 5 February 2001. Accessed at: http:// www.silicon.com/public/door? REQUNIQ $=981296287$ \& 6004REQEVENT $=\&$ REQINT $1=42463$ \&

35 Too hot to handle: Beijing bans online tobacco, sex ads-and a lot more. China Online. 16 April 2001. Accessed at: http://www.chinaonline.com/issues/ internet_policy/newsarchive/secure/2001/april/ B101041215.as p.

36 Richtel M. Online alcohol vendors confront prohibition's legacy. New York Times. 8 August 1998

37 Wine industry joins e-commerce craze. Associated Press. 3 February 2000. Accessed at: www.jointogether.org.

38 Online wine sales turn into industry battle. IDG. 13 April 1999. Accessed at: www.jointogether.org.

39 United States General Accounting Office. Internet pharmacies: adding disclosure requirements would aid state and federal oversight. Washington DC: General Accounting Office, 2000.

40 President's Working Group on Unlawful Conduct on the Internet. The electronic frontier: the challenge of unlawful conduct involving the use of the internet. March 2000.

41 Texas sues Internet tobacco seller. United Press International. December 2000. Accessed at: www.vny.com/cf/News/ upidetail.cfm.

42 Michigan cracks down on on-line cigarette sales. The (Toronto) Globe and Mail. 28 September 2000

43 Web cigarette sales said taxed. Associated Press. 15 January 2000. Accessed at: www.jointogether.org.

44 Streitfeld D. Online tobacco sales ignite fight over taxes. Washington Post. 29 August 2000;A1.

45 Wolverton T, Sandoval G. Taxes threaten booming sales of cigarettes online. CNET News. 19 February 2000.

46 Samuelson A. Internet buyers owe taxes on cigarettes. MediaNews Group. 20 January 2000.

47 Yach D, Bettcher D. Globalization of tobacco industry influence and new global responses. Tobacco Control 2000; 9:206-16. 